\title{
POLA KOMUNIKASI DAN ADAPTASI BUDAYA MAHASISWA ASING DI UNIVERSITAS PRIMA INDONESIA
}

\author{
Christin Agustina Purba ${ }^{1}$, Yolanda Novita Silaban ${ }^{2}$ \\ Dosen Fakultas Keguruan dan Ilmu Pendidikan \\ Prodi Pendidikan Bahasa dan Sastra Indonesia \\ Prodi Pendidikan Bahasa Inggris \\ Corresponding Author: christinpurba@unprimdn.ac.id
}

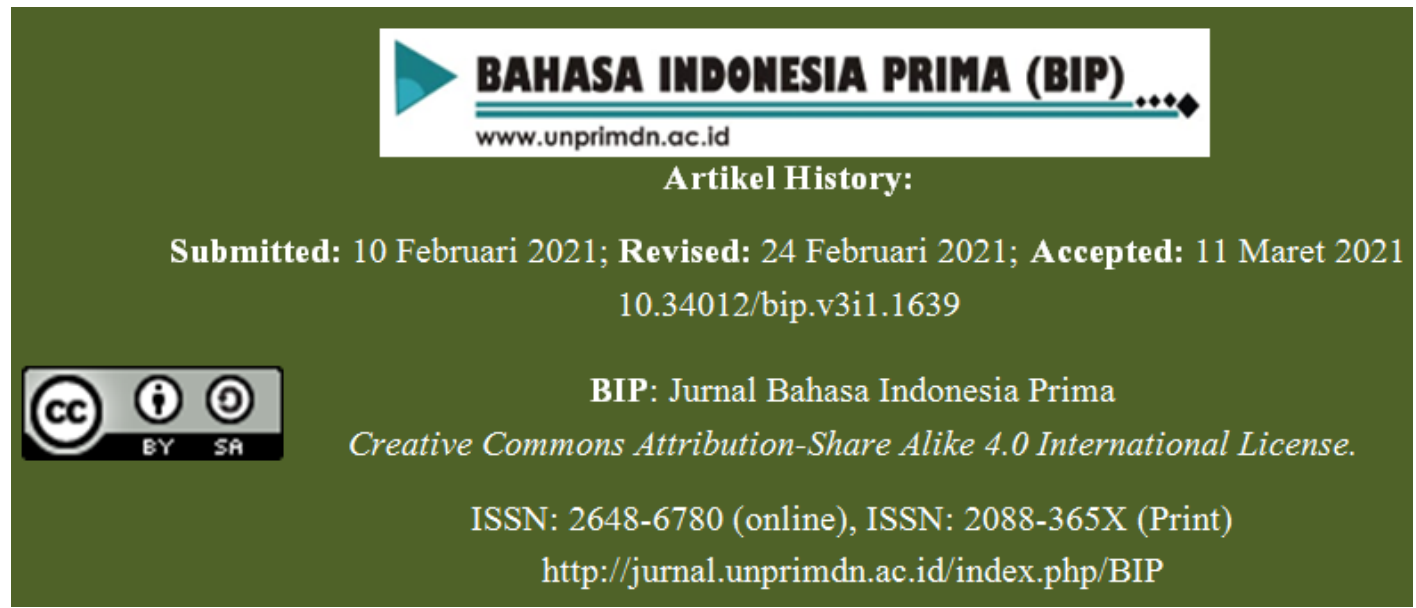

Abstrak-Penelitian ini bertujuan menganalisis pola komunikasi dan adaptasi budaya mahasiswa asing yang sedang studi di Universitas Prima Indonesia. Pola komunikasi dan adaptasi budayaa tersebut dilihat melalui penyesuaian proses komunikasi yang terjadi dalam setiap interaksi diantara para mahasiswa asing serta proses menyesuaikan diri dengan orangorang, lingkungan, dan kelompok-kelompok baru yang mereka temui. Sebagai penelitian deskriptif kualitatif, penentuan subjek penelitian menggunakan teknik purposive sampling dengan informan mahasiswa asing yang berasal dari Vietnam dan Korea Selatan di Universitas Prima Indonesia Tahun akademik 2019/2020, pimpinan Unit kerja terkait, dan pihak-pihak lain yang relevan. Data yang digunakan berupa data primer dan data sekunder. Teknik pengumpulan data melalui observasi, wawancara mendalam dan dokumentasi. Penelitian ini menggunakan analisis tematik, dan koding yang digunakan dalam proses analisa data adalah open coding, axial coding dan selective coding. Hasil penelitian menyimpulkan bahwa pola komunikasi mahasiswa asing dengan sekitarnya mengalami kesulitan meskipun terbatasnya waktu bagi mereka untuk berinteraksi menimbulkan permasalahan-permasalahan dalam proses adaptasi misalnya berkaitan dengan makanan, gaya hidup, pertemanan dan iklim. Perbedaan cara berperilaku saat berkomunikasi baik secara verbal maupun nonverbal, seperti gerak tubuh, nada suara, perbedaan selera dan lain-lain yang teramati saat mahasiswa asing berinteraksi di lingkungan kampus.dan kegiatan sosial keagamaan. Umumnya mereka berusaha untuk menyesuaikan sendiri dengan lingkungan dan budaya lokal. Diperlukan proses dalam adapatasi baik dari segi komunikasi maupun kebiasaan. Masing-masing informan membutuhkan masa yang berbeda-beda yakni sekitar satu sampai tiga bulan mereka bisa beradaptasi dan berakulturasi dengan budaya di Medan.

Kata Kunci: adaptasi budaya, pola komunikasi 


\section{A. Pendahuluan}

Dalam bermasyarakat akan selalu ada komunikasi untuk menjalin sebuah hubungan. Dengan adanya komunikasi kita akan mengetahui tentang berbagai hal antara satu dengan yang lainnya Sebagai makhluk sosial manusia yang tidak dapat hidup sendiri. Manusia akan selalu berhubungan dengan manusia lainnya yang berasal dari berbagai bangsa. Melalui komunikasi dengan orang lain, kita dapat memenuhi kebutuhan emosional dan. intelektual kita. Untuk berhubungan dengan orang lain itulah dibutuhkan komunikasi, baik komunikasi secara verbal maupun komunikasi secara non verbal. Indonesia sebagai bangsa dan negara sangat terbuka dalam peran dan pergaulan internasional, banyak andil dalam mengambil peranan dalam masalah perdamaian, ekonomi, politik, budaya dan lain-lain, termasuk dibidang pendidikan. Pemerintah Indonesia membuka kesempatan dan bentuk kerjasama bagi mahasiswa asing yang ingin belajar di Indonesia. Dalam belajar di kampus mahasiswa tidak mungkin sendiri, selalu ada orang lain yang dibutuhkan untuk menggali dan mengembangkan potensi yang dimiliki. Komunikasi antarbudaya tidak hanya sekedar sebuah proses hubungan dan interaksi antara seseorang berkebangsaan Indonesia dengan seseorang berkebangsaan lainya. Lebih dari itu, komunikasi antarbudaya berarti juga menuntut usaha dan kemampuan menangkap, utamanya, simbol-simbol nonverbal yang menjadi bagian dari budaya masing-masing individu seseorang dalam menjalani proses komunikasi berbeda budaya pasti akan mengalami suatu keterkejutan budaya yang berbeda dengan budaya asalnya, yang biasa disebut dengan gegar budaya (culture shock). Tanda-tanda atau petunjuk-petunjuk itu meliputi seribu satu cara yang kita lakukan dalam mengendalikan diri kita sendiri dalam menghadapi situasi sehari-hari. Hal ini jugalah yang dialami mahasiswa asing yang saat ini sedang menuntu Ilmu di Universitas Prima Indonesia. Mereka berasal dari beberapa negera ada yang berasal dari Vietnam dan Korea selatan. Mereka belajar seperti mahasiswa reguler lainnya, sehingga banyak hal yang harus mereka selaraskan. Terutama dalam proses pembelajaran, mahasiswa yang berasal dari Korea Selatan saat ini menuntut ilmu di Prodi Pendidikan Bahasa dan Sastra Indonesia dan mereka masuk dalam kelas regular bergabung dengan mahasiswa lainnya.

Dalam penanganan dan proses adapatasi ini, kemampuan komunikasi menjadi salah satu faktor pendukung bagi mahasiswa asing dalam proses pembelajaran yang mereka laksanakan. Dari permasalahan tersebut, penelitian ini ingin menggambarkan :

1) Adakah hambatan komunikasi dalam proses adapatasi budaya dengan lingkungan saat ini?

2) Bagaimana pola komunikasi mahasiswa asing dalam berkomunikasi di dalam proses belajar di kelas dan dengan lingkungan sekitar.

\section{Kerangka Teori}

1) Komunikasi

Pola komunikasi adalah representasi dari suatu peristiwa komunikasi yang dapat digunakan untuk melihat unsurunsur yang terlibat dalam komunikasi. Pola komunikasi biasa disebut juga sebagai model dari proses komunikasi, sehingga dengan adanya berbagai macam model komunikasi dan bagian dari proses 
komunikasi akan dapat ditemukan pola yang cocok dan mudah digunakan dalam berkomunikasi. Secara umum pola komunikasi dapat diartikan sebagai suatu model proses penyampaian informasi. Penelitian ini bertujuan untuk menggambarkan pola komunikasi antarbudaya yang terbentuk dari para mahasiswa asing dalam lingkungan belajarnya. Dalam tahapannya pola komunikasi tersebut dieksplorasi melalui perilaku-perilaku komunikasi yang khas dan berulang yang terjadi dalam setiap interaksi diantara para mahasiswa asing, terutama saat mahasiswa asing masuk dan menyesuaikan diri dengan orang-orang, lingkungan, dan kelompok- kelompok baru yang mereka temui. Bahasa adalah sebagai salah satu hal yang memperlancar sebuah komunikasi. Bahasa yang berbeda-beda dari latar belakang yang beda, menjadi kendala bagi beberapa orang untuk berkomunikasi dengan orang-orang dari negara lain dengan bahasa yang berbeda dari bahasa ibunya. Menurut Owen dalam Setiawan (2006:1), "bahasa adalah kode yang diterima secara sosial atau sistemkonvensional untuk menyampaikan konsep melalui kegunaan simbol-simbol yang dikehendaki dan kombinasi simbolsimbol yang diatur oleh ketentuan”.

2) Adaptasi Budaya

Adaptasi merupakan suatu jembatan yang perlu dilewati agar individu atau sekelompok orang berkomunikasi dengan pihak lain yang berbeda budaya. Adaptasi dalam kajian komunikasi antar budaya pada umumnya dihubungkan dengan perubahan dari masyarakat atau bagian dari masyarakat (Utami, 2015). Orang yang cepat beradaptasi cenderung memiliki kesadaran dan kepekaan terhadap lingkungannya, sehingga dapat segera siap untuk berubah dan mengubah perilaku.
Ada banyak hal yang memotivasi orang untuk beradaptasi Brent D. Ruben dan Lea P. Stewart (2013: 375) mengutip Young Yun Kim dan menguraikan serta menggambarkan langkah-langkah dalam proses pengadaptasian sebuah budaya. Secara umum ada empat fase (fase honeymoon, fase frustasi, fase readjustment, dan fase resolution) ditambah dengan fase perencanaan.

a. Fase Perencanaan adalah fase di mana seseorang masih berada pada kondisi asalnya dan menyiapkan segala sesuatu

b. Fase Honeymoon adalah fase dimana seseorang mengalami kegembiraan sebagai reaksi awal dari sebuah kekaguman, penuh semangat akan hal-hal baru, antusias, ramah, dan mempunyai hubungan yang baik dengan penduduk sekitar

c. Fase Frustasi adalah fase di mana daya tarik akan hal-hal baru dari seseorang perlahan-lahan mulai berubah menjadi rasa frustasi

d. Fase Readjustment adalah fase di mana seseorang mulai menyelesaikan krisis yang dialami pada fase frustasi

e. Fase Resolution adalah fase terakhir dari proses adaptasi budaya ini berupa jalan terakhir yang diambil seseorang sebagai jalan keluar dari ketidaknyamanan yang dirasakannya. Di fase ini ada beberapa hal yang dapat dijadikan pilihan, yaitu: Flight (memutuskan untuk meninggalkan lingkungan), Fight (memutuskan untuk tetap bertahan dan berusaha menghadapi segala hal), Accommodation (kompromi), dan Full Participation (enjoy).

\section{B. Metodologi}


Penelitian ini menggunakan paradigma konstruktivisme. Peneliti merasa paradigma konstruktivisme dengan menggunakan teknik analisa data kualitatif. Analisa data dibahas dengan kerangka pemikiran dari proses adaptasi budaya Gudykunt \& Kim (2003) dalam proses komunikasi yang terjadi diantar mahasiswa asing di Universitas Prima Indonesia.

\section{Hasil dan Kesimpulan}

a. Karakateristik Mahasiswa Asing Universitas Prima Indonesia.

Mahasiswa asing yang yang menajdi informan dalam penelitian ini adalah mahasiswa yang berasal dari Vietnam dan Korea Selatan yang saat ini sedang kuliah di Program Studi S1 Kedokteran Gigi dan S1 Pendidikan Bahasa dan Sastra Indonesia di Universitas Prima Indonesia yang diharapakan melalui penelitian ini mendapatkan gambaran pola komunikasi yang berbeda-beda diantara para mahasiswa asing pada saat beradaptasi dengan lingkungan baru yang mereka hadapi baik didalam maupun diluar kelas.

\section{Tabel 1}

Fase adaptation pada informan

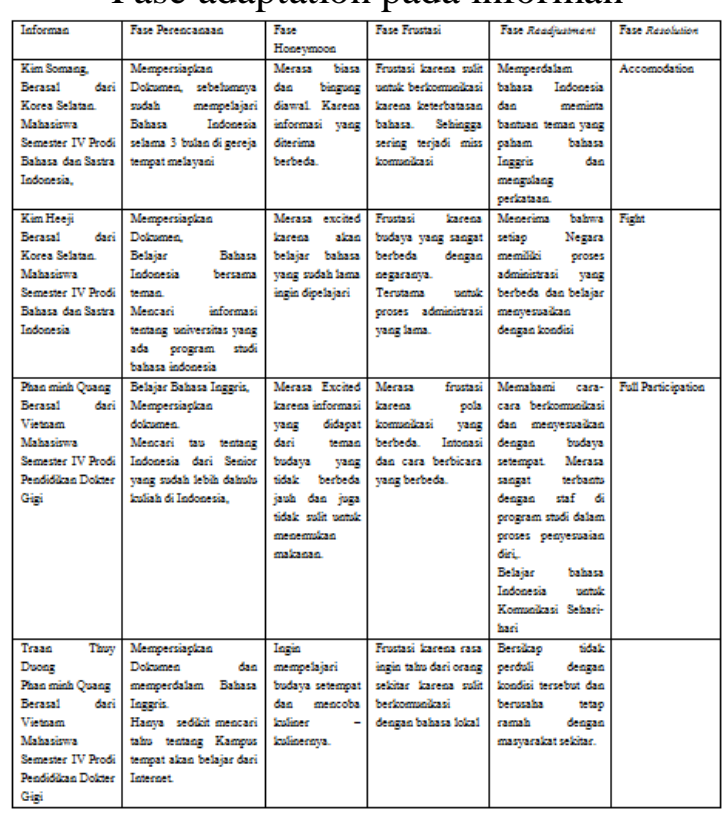

a. Proses Adaptasi Budaya
Penelitian ini bertujuan untuk melihat bagaimana pola komunikasi dan adaptasi mahasiswa asing yang ada di Universitas Prima Indonesia. Kemudian hasil obseravasi dan wawancara dengan mahasiswa tersebut coba dieksplorasi melalui tindakan dan perilaku mereka selama di kelas, berinteraksi dengan dosen, tenaga kependidikan dan teman teman sekelas mereka. Dan juga melihat komunikasi yang terjadi dalam setiap hari nya. Hanya saja pada saat penelitian ini dilaksanakan terjadi pandemic covid-19 sehingga observasi lapangan tidak maksimal dilaksanakan. Penelitian dilaksanakan via whats app ataupun aplikasi zoom.

Mahasiswa Asing yang berasal dari berbagai negara dalam menjalani kehidupan selama menyelesaikan masa pendidikan di Universitas Prima Indonesia dalam keseharian mereka memerlukan proses adaptasi atau penyesuaian diri terhadap lingkungan sosial budaya yang baru. Adaptasi tersebut dapat dilihat dari bahasa, tempat tinggal, lingkungan, serta kondisi budaya yang cukup jauh berbeda yang mengharuskan mereka untuk menyelesaikan setiap persoalaan kebudayaan secara baik sehingga tidak berbenturan dan menyebabkan mereka tidak mampu dalam menyesuaikan diri dengan lingkungannya.

Berdasarkan penuturan para informan mengenai proses adaptasi dilaksanakan mereka dengan cara mengikuti pola kebiasaan sehari-hari lingkungan sekitar mereka saat ini. Para informan memilih cara beradaptasi dengan menyesuaikan diri dengan orang-orang dan kebudayaan setempat. Mahasiswa yang berasal dari Vietnam saat ini tinggal di dormitory yang ada di kampus, sementara mahasiswa yang berasal dari Korea mereka tinggal sendiri 
dengan mengontrak sebuah rumah didekat kampus.

Dalam pola komunikasi antara para mahasiswa asing dengan mahasiswa Indonesia lainnya di dalam mereka dapat mengikuti interaksi dengan sesama teman sekelas. Pola komunikasi yang digunakan oleh mahasiswa asing tersebut adalah menggunaka komunikasi interpersonal, yaitu dimulai dengan melakukan pengenalan budaya terlebih dahulu sebelum berada di Indonesia, setelah berada di Indonesia mereka mengalami culture shock dan cara mengatasinya dengan meminta saran kepada teman sesama mahasiswa asing ataupun dengan teman mahasiswa lokal bagaimana cara beradaptasidengan budaya dan negara baru. Penggunaan bahasa Indonesia yang tidak sesuai dengan kaidah menjadikan komunikasi menjadi terhambat, karena sebagian besar mahasiswa asing mempelajari Bahasa Indonesia sesuai dengan kaidahnya. Namun mereka sedikit kesulitan untuk memaknai intonasi karena perbedaan dialek ataupun perilaku saat berkomunikasi baik secara verbal maupun nonverbal.adanya perbedaan tone suara, kecepatan bicara, maupun ekpresi wajah yang teramati saat mahasiswa asing menyapa, berkenalan, berdiskusi ataupun pada saat mahasiswa asing melakukan presentasi dikelas, Namun permasalahan dalam pola komunikasi tersebut dapat mereka atasi seiring dengan makin seringnya mereka berinteraksi dengan lingkungan sekitar. Mahasiswa merasa banyak terbantu oleh staff di program studi dalam beradaptasi dengan lingkungan sekitar.Mereka bahkan sudah berani mencoba untuk membeli makanan local disekitar dormitory.

Beberapa mahasiswa yang berasal dari Vietnam bahkan mencoba untuk belajar
Bahasa Indonesia meskipun itu hanya bahasa yang biasa digunakan untuk komunikasi sehari-hari mereka dengan lingkungan sekitar mereka.beberapa masalah. Proses pengenalan hingga pertemanan dilalui oleh mahasiswa asing dengan mahasiswa lokal. Dapat dikatakan bahwa mereka telah melalui beberapa tahap dalam penyesuain dengan kondisi sosial. Hubungan social mereka berkembang dari yang tidak mengenal dan menjadi hubungan pertemanan. Pertama, hubungan komunikasi antara seseorang dengan orang lain dimulai pada tahap superfisial dan bergerak pada sebuah kontinum menuju tahap yang lebih intim (West dan Lynn, 2008: 197). Dan tidak jarang mereka keluar bersama sekedar untuk lebih memahami budaya dan kultur local. Mahasiswa dari Korea Selatan mengatakan pada awal memulai perkuliahan dia sedikit terkejut dengan kondisi perkuliahan yang berbeda dengan Negara asalnya. Ditambah kendala dalam bahasa karena bahasa pengantar yang digunakan adalah Bahasa Indonesia. Seiring dengan berjalan nya waktu dapat

\section{Kesimpulan}

Mahasiswa Asing di Universitas Prima Indonesia dalam berkomunikasi kesehraiannya memiliki kendala namun masing-masing mereka mencoba dengan berbagai cara dalam menyesuaikan diri terhadap lingkungan budaya baru. Terbatasnya waktu bagi mereka untuk berinteraksi menimbulkan permasalahanpermasalahan dalam proses adaptasi misalnya berkaitan dengan makanan, gaya hidup, pertemanan dan iklim. Umumnya mereka berusaha untuk menyesuaikan sendiri dengan lingkungan dan budaya lokal. Beberapa dari mereka ada yang memilih konsep diri dan diri dalam mengatasi permasalahan dalam proses 
adaptasi budaya, di mana mereka berkompromi dengan budaya yang baru, namun tetap memiliki batasan di mana mereka memilih Budaya Indonesia mana sajakah yang dapat mereka ikuti dan tidak. Ada yang memilihi untuk bertanya dengan sesama teman mahasiswa lokal sebagai informan mereka tentang budaya setempat, ada juga yang mencari tahu dari staff di kampus dan juga dosen-dosen mereka mengajar.

Begitu juga dengan komunikasi seharihari dengan lingkungan sekitar mereka memilih dengan prinsip keterbukaaan. Dengan teman sekelas ataupun dosen mereka Memulai lebih awal untuk berkomunikasi. Namun dengan masyarakat sekitar mereka tinggal mereka masih memilih untuk berhati-hati dalam berkomunikasi. Perbedaan cara berperilaku saat berkomunikasi baik secara verbal maupun nonverbal, seperti gerak tubuh, nada suara, perbedaan selera dan lain-lain yang teramati saat mahasiswa asing berinteraksi di lingkungan kampus dan kegiatan sosial keagamaan. Umumnya mereka berusaha untuk menyesuaikan sendiri dengan lingkungan dan budaya local.

\section{Daftar Pustaka}

Dedi Mulyana. 2014. Komunikasi Antarbudaya panduan berkomunikasi dengan orang-orang berbeda budaya, Bandung : PT. Remaja Rosdakarya.

\section{Cultures And}

Communication, An Indonesian Scholar's Perspective. PT. Remaja Rosdakarya: Bandung.

Amanah, Siti. 2015. Pola Komunikasi dan Proses Akulturasi Mahasiswa Asing di STAIN Kediri. Realita. Vol. 13, No. 1.

Setyo Utami. 2015., Teori-teori Adaptasi Budaya. Jurnal Komunikasi Vol 7. Untar.

Abidin, Yunus,dkk. 2010. Kemampuan Berbahasa Indonesia di Perguruan Tinggi. Bandung: CV. Maulana Media Grafika.

Gudykunst, William B dan Bella Mody, 2002. Handbook of International and Intercultural Communication. 2nd Edition. California: Sage Publications.

Wolcott, H.R. 1990. Qualitative inquiry in education: The continuing debate. The American Jurnal of Occupational Therapy. California: Sage Publication. 